\title{
Development of Physical Qualities in Children 6-7 Summer Age with Primary Use of Means of Gymnastics
}

\author{
DjamshidUmarovXasanovich,
}

The candidate of pedagogical sciences, the senior lecturer, the Uzbek state university of physical training and sports, Tashkent

\begin{abstract}
Purpose is working out and realisation of a technique of carrying out of lessons of physical training in the first classes with primary use of means of gymnastics. During work carrying out studying and the analysis of the scientifically-methodical literature was spent, methods of pedagogical supervision, pedagogical testing of physical readiness, heart rate monitoring, and also methods of mathematical statistics were used. The offered technique represents introduction of the developed complexes of exercises during the lessons of physical training directed on development of the basic physical qualities and increase of health of pupils of the first classes, and also for entering of emotional colouring and interest. Use of an offered technique of training to exercises with primary use of means of gymnastics has allowed to raise a number of indicators of impellent abilities statistically essentially.
\end{abstract}

Keywords: physical training, younger schoolboys, lesson structure, educational process, gymnastics means, gymnastic exercises, impellent abilities, physical qualities, physical readiness, heart rate monitoring.

Article Received: 16th October, 2020; Article Revised: 30th December, 2020; Article Accepted: 08th January, 2021

INTRODUCTION.Physical training as the component of the general culture of a society, is directed on health strengthening, development physical, moral-strong-willed and mental abilities for the purpose of harmonious formation of the person and development of active ability to live.

Value of physical training during the school period of human life consists in creation of the base to all-round physical development, strengthening of health, formation of various impellent skills. Here it leads to occurrence of objective preconditions for harmonious development of the person. High-grade development of children of school age without active sports employment is practically unattainable $[1,2]$.

MAIN PART.The analysis of the scientifically-methodical literature shows, that to one of the necessary means providing versatile and harmonious physical development, and education of younger schoolboys, gymnastic exercises are. The gymnastics has educational and developmental orientation and promotes versatile, harmonious development and perfection of impellent functions of pupils. Gymnastics exercises are important and as means of formation of a correct bearing and culture of movements of children of younger school age [3,4].

Student teaching and conversations with teachers of physical culture allow to notice, that many exercises of gymnastics, especially exercises on a gymnastic apparatus, acrobatics elements, complexes of free exercises and others, are considered rather labour-consuming and demanding considerable expenses of time and forces of pupils and teachers of physical culture. Thereupon, in the conditions of constant deficiency of time which is taken away on physical culture lessons at school, Undeservedly little attention is paid to gymnastic exercises. Employment on gymnastics with younger schoolboys are quite often replaced with other kinds of physical 
exercises that leads to incomplete performance by pupils of the program on gymnastics. The specified lacks lead to decrease in interest of pupils to gymnastic exercises and mass character of its development among schoolboys

The analysis of the scientificallymethodical literature specify in necessity of search of new ways of increase of efficiency of carrying out of a lesson of physical training and revealing most effective remedies for development of physical qualities of children of younger school age $[5,6,10]$.

Thereupon necessity of carrying out of the research directed on working out of a technique with primary use of means of gymnastics for intensive development of physical qualities becomes aggravated, using which, it would be possible to provide rational dispensing of loadings in the course of physical training of children 6-7 summer age, to increase level of physical readiness and to raise interest of schoolboys to lessons of physical training [7].

In this connection the purpose of our work is working out and realisation of a technique of carrying out of lessons of physical training in the first classes with primary use of means of gymnastics. It is supposed, what exactly primary use of means of gymnastics at lessons of physical training of first-graders can provide growth of level of physical readiness, development and perfection of physical qualities. The complexes of exercises besides, developed by us will help to expand volume of their impellent skills and to raise interest to employment by physical training $[8,9]$.

For achievement of objects in view we have tried to solve following problems:

1. To develop complexes of exercises with expanded use of means of the gymnastics, directed on development of physical qualities of children 6-7 summer age.

2. To develop a technique of carrying out of lessons of physical training in the first classes on the basis of the developed complexes and to prove its efficiency within the limits of a practical training physical training.

During scientific research we had been used following methods:

- Studying and the analysis of the scientifically-methodical literature,

- Pedagogical supervision,

- Pedagogical testing of physical readiness,

- heart rate monitoring, pedagogical experiment,

- Methods of mathematical statistics.

Research was spent to three consecutive stages.

The first stage has been devoted studying of references on a problem, the analysis of its historical and modern condition. At this stage problems and a research hypothesis have been formulated the purpose.

The second stage consisted in experimental check of a hypothesis of research, substantive provisions for the purpose of their specification and acknowledgement. Preparation and working out of an experimental technique was carried out; selection of control exercises for increase of level of physical development of pupils of the first classes. For a substantiation of a technique of employment by gymnastics at physical training lessons in an elementary school it was necessary to reveal, what options

of physical and functional readiness are the most significant at younger school age. During training and perfection of physical qualities of children 6-7 summer age have been made preliminary experiment which consisted in selection of complexes of exercises for more effective development of the basic physical qualities. By results of preliminary experiment the program of employment and separate elements of a technique have been corrected.

The third stage included carrying out of pedagogical experiment on revealing of efficiency of employment by the physical training spent on the basis of the 
developed technique. During pedagogical experiment two times in educational year (in the autumn and in the spring) were carried out researches of physical readiness. In pedagogical experiment (50 pupils of 1 classes participated in experimental group of 25 schoolboys, in control group - 25 schoolboys, from them 12 boys and 13 girls in each group). At the same stage processing and the analysis of results of an experimental research was carried out, research materials were systematised.

For the purpose of all-round physical development of schoolboys the technique of application of means of gymnastics in the first classes on which basis complexes of exercises for development of physical qualities have been made has been developed and are introduced in a lesson of physical training for pupils of the first classes. This technique allows to solve consistently problems of physical training of schoolboys throughout a year of training at school, forming at pupils complete representation about physical training, its possibilities in increase of working capacity and improvement of a state of health, and the main thing - bringing up the person capable to independent, creative activity.

In comparison with the traditional program application of an offered experimental technique gives advantages as promotes versatile physical preparation of children, making positive impact on dynamics of indicators of physical readiness.

Table 1

Level of physical readiness of pupils of the first classes of control and experimental groups at the moment of the termination of two-month preliminary experiment (Boys)

\begin{tabular}{|c|c|c|c|c|}
\hline Control exercises & Group & $\mathrm{X} \pm \sigma$ & t st. & $\mathrm{P}$ \\
\hline Run 30m (s) & $\begin{array}{l}\mathrm{CG} \\
\mathrm{EG}\end{array}$ & $\begin{array}{l}7,46 \pm 0,08 \\
7,41 \pm 0,12\end{array}$ & 0,37 & $p>0,05$ \\
\hline Shuttle run $3 \times 10 \mathrm{~m}(\mathrm{~s})$ & $\begin{array}{l}\text { CG } \\
\text { EG }\end{array}$ & $\begin{array}{l}11,18 \pm 0,11 \\
11,38 \pm 0,13\end{array}$ & 1,14 & $p>0,05$ \\
\hline Broad jump about places (sm) & $\begin{array}{l}\text { CG } \\
\text { EG }\end{array}$ & $\begin{array}{l}114,29 \pm 1,78 \\
115,86 \pm 1,92\end{array}$ & 0,60 & $p>0,05$ \\
\hline $\begin{array}{l}\text { Flexion and extension of the arms in } \\
\text { the lying position (times) }\end{array}$ & $\begin{array}{l}\text { CG } \\
\text { EG }\end{array}$ & $\begin{array}{l}3,14 \pm 0,29 \\
3,36 \pm 0,37\end{array}$ & 0,45 & $\mathrm{p}>0,05$ \\
\hline $\begin{array}{l}\text { Raising straight legs on the gymnastic } \\
\text { wall (times) }\end{array}$ & $\begin{array}{l}\text { CG } \\
\text { EG }\end{array}$ & $\begin{array}{l}5,78 \pm 0,35 \\
6,29 \pm 0,53\end{array}$ & 0,79 & $\mathrm{p}>0,05$ \\
\hline High bar pull-up (times) & $\begin{array}{l}\text { CG } \\
\text { EG }\end{array}$ & $\begin{array}{l}1,71 \pm 0,26 \\
1,57 \pm 0,25\end{array}$ & 0,39 & $\mathrm{p}>0,05$ \\
\hline $\begin{array}{l}\text { Raising the torso from a prone } \\
\text { position, hands behind the head in } 30 \\
\text { seconds (times) }\end{array}$ & $\begin{array}{l}\text { CG } \\
\text { EG }\end{array}$ & $\begin{array}{l}10,50 \pm 0,50 \\
10,86 \pm 0,56\end{array}$ & 0,47 & $p>0,05$ \\
\hline Sitting forward bend (sm) & $\begin{array}{l}\text { CG } \\
\text { EG }\end{array}$ & $\begin{array}{l}0,57 \pm 0,10 \\
0,93 \pm 0,83\end{array}$ & 0,98 & $p>0,05$ \\
\hline $\begin{array}{l}\text { "Bridge" from the supine position } \\
(\mathrm{sm})\end{array}$ & $\begin{array}{l}\text { CG } \\
\text { EG }\end{array}$ & $\begin{array}{l}66,49 \pm 0,57 \\
65,99 \pm 0,38\end{array}$ & 0,73 & $p>0,05$ \\
\hline Dynamometry (kg) & $\begin{array}{l}\text { CG } \\
\text { EG }\end{array}$ & $\begin{array}{l}10,66 \pm 0,18 \\
11,32 \pm 0,19\end{array}$ & 2,58 & $p>0,05$ \\
\hline
\end{tabular}




\begin{tabular}{|l|l|l|l|l|}
\hline & CG & $3,97 \pm 0,13$ & 1 \\
Romberg test $(\mathrm{s})$ & EG & $4,17 \pm 0,15$ & & $\mathrm{p}>0,05$ \\
\hline
\end{tabular}

The offered technique represents introduction of the developed complexes of exercises during the lessons of physical training directed on development of the basic physical qualities and increase of health of pupils of the first classes, and also for entering of emotional colouring and interest.

All made complexes of exercises have the certain structure, including following groups of exercises:

- - exercises for the development of speed-strength abilities;

- - strength exercises;

- - exercises for the development of agility;

- - exercises to develop flexibility.

The structure of employment included various variants of carrying out which differed selection of means, dispensing of separate loadings, rate of performance,

Table 2

Level of physical readiness of pupils of the first classes of control and experimental groups at the moment of the termination of two-month preliminary experiment (Girls)

\begin{tabular}{|l|l|l|l|l|}
\hline Control exercises & Group & $\mathrm{X} \pm \sigma$ & $\mathrm{t}$ st. & $\mathrm{P}$ \\
\hline Run 30m (s) & CG & $7,84 \pm 0,10$ & 1,35 & $\mathrm{p}>0,05$ \\
\hline Shuttle run 3x10m (s) & CG & $\begin{array}{l}11,84 \pm 0,13 \\
11,73 \pm 0,15\end{array}$ & 0,54 & $\mathrm{p}>0,05$ \\
\hline Broad jump about places (sm) & CG & $\begin{array}{l}108,00 \pm 1,40 \\
110,09 \pm 1,49\end{array}$ & 1,92 & $\mathrm{p}>0,05$ \\
\hline $\begin{array}{l}\text { Flexion and extension of the arms in } \\
\text { the lying position (times) }\end{array}$ & $\mathrm{EG}$ & $\begin{array}{l}3,73 \pm 0,27 \\
3,64 \pm 0,43\end{array}$ & 0,18 & $\mathrm{p}>0,05$ \\
\hline $\begin{array}{l}\text { Raising straight legs on the gymnastic } \\
\text { wall (times) }\end{array}$ & $\mathrm{CG}$ & $\begin{array}{l}4,27 \pm 0,33 \\
4,54 \pm 0,37\end{array}$ & 0,55 & $\mathrm{p}>0,05$ \\
\hline $\begin{array}{l}\text { High bar pull-up (times) } \\
\text { EG }\end{array}$ & $\begin{array}{l}\text { CG } \\
\text { EG }\end{array}$ & $\begin{array}{l}2,54 \pm 0,37 \\
2,72 \pm 0.47\end{array}$ & 0,31 & $\mathrm{p}>0,05$ \\
\hline $\begin{array}{l}\text { Raising the torso from a prone } \\
\text { position, hands behind the head in 30 } \\
\text { seconds (times) }\end{array}$ & $\mathrm{EG}$ & $\begin{array}{l}8,54 \pm 0,51 \\
9,91 \pm 0,64\end{array}$ & 1,67 & $\mathrm{p}>0,05$ \\
\hline
\end{tabular}




\begin{tabular}{|l|l|l|l|l|}
\hline Sitting forward bend (sm) & CG & $\begin{array}{l}1,25 \pm 038 \\
2,82 \pm 0,44\end{array}$ & 1,72 & $\mathrm{p}>0,05$ \\
\hline "Bridge" from the supine position & $\begin{array}{l}\text { CG } \\
\text { (sm) }\end{array}$ & $\begin{array}{l}55,32^{\wedge} 0,35 \\
54,63 \pm 0,34\end{array}$ & 1,43 & $\mathrm{p}>0,05$ \\
\hline Dynamometry (kg) & CG & $\begin{array}{l}10,05 \pm 0,17 \\
10,65 \pm 0,25\end{array}$ & 1,97 & $\mathrm{p}>0,05$ \\
\hline EG & CG & $\begin{array}{l}4,34 \pm 0,13 \\
4,80 \pm 0,25\end{array}$ & 1,60 & $\mathrm{p}>0,05$ \\
\hline
\end{tabular}

Results of the statistical analysis of indicators of physical readiness of pupils of the first classes after carrying out of preliminary experiment are reflected in tables 1 and 2. Apparently from these tables to the lagging behind parties of physical preparation of pupils it is necessary to carry indicators of speed-strength training, force, flexibility and speed. By results of preliminary experiment we had been spent correction made before the experimental program. In particular, complexes of exercises for development of the basic physical qualities (speed-power, force, dexterity, flexibility, speed), 6-7 summer age comprehensible to children which were applied further in the basic pedagogical experiment have been made.

Table 3

Dynamics of indicators of physical readiness of pupils of the first classes of control and experimental groups at the moment of the termination of pedagogical experiment (boys)

\begin{tabular}{|c|c|c|c|c|}
\hline Control exercises & Group & $\mathrm{X} \pm \sigma$ & t st. & $\mathrm{P}$ \\
\hline Run 30m (s) & $\begin{array}{l}\mathrm{CG} \\
\mathrm{EG}\end{array}$ & $\begin{array}{l}6,93 \pm 0,11 \\
5,67 \pm 0,07\end{array}$ & 9,29 & $\mathrm{p}<0,01$ \\
\hline Shuttle run $3 \times 10 \mathrm{~m}(\mathrm{~s})$ & $\begin{array}{l}\text { CG } \\
\text { EG }\end{array}$ & $\begin{array}{l}10,72 \pm 0,09 \\
10,16 \pm 0,12\end{array}$ & 3,72 & $\mathrm{p}<0,01$ \\
\hline Broad jump about places (sm) & $\begin{array}{l}\text { CG } \\
\text { EG }\end{array}$ & $\begin{array}{l}119,57 \pm 1,18 \\
126,29 \pm 1,10\end{array}$ & 4,17 & $\mathrm{p}<0,01$ \\
\hline $\begin{array}{l}\text { Flexion and extension of the arms in the } \\
\text { lying position (times) }\end{array}$ & $\begin{array}{l}\text { CG } \\
\text { EG }\end{array}$ & $\begin{array}{l}4,71 \pm 0,32 \\
5,71 \pm 0,44\end{array}$ & 1,84 & $\mathrm{p}>0,01$ \\
\hline $\begin{array}{l}\text { Raising straight legs on the gymnastic wall } \\
\text { (times) }\end{array}$ & $\begin{array}{l}\text { CG } \\
\text { EG }\end{array}$ & $\begin{array}{l}6,57 \pm 0,36 \\
11,36 \pm 0,54\end{array}$ & 7,37 & $\mathrm{p}<0,01$ \\
\hline High bar pull-up (times) & $\begin{array}{l}\mathrm{CG} \\
\mathrm{EG}\end{array}$ & $\begin{array}{l}2,64 \pm 0,32 \\
4,86 \pm 0,29 \\
\end{array}$ & 5,05 & $\mathrm{p}<0,01$ \\
\hline $\begin{array}{l}\text { Raising the torso from a prone position, } \\
\text { hands behind the head in } 30 \text { seconds (times) }\end{array}$ & $\begin{array}{l}\text { CG } \\
\text { EG }\end{array}$ & $\begin{array}{l}12,79 \pm 0,41 \\
14,64 \pm 0,50\end{array}$ & 2,88 & $\mathrm{p}<0,01$ \\
\hline Sitting forward bend (sm) & $\begin{array}{l}\text { CG } \\
\text { EG }\end{array}$ & $\begin{array}{l}1,36 \pm 0,20 \\
2,57 \pm 0,33\end{array}$ & 3,17 & $\mathrm{p}<0,01$ \\
\hline "Bridge" from the supine position (sm) & $\begin{array}{l}\text { CG } \\
\text { EG }\end{array}$ & $\begin{array}{l}63,39 \pm 0,42 \\
60,29 \pm 0,36\end{array}$ & 5,55 & $\mathrm{p}<0,01$ \\
\hline Dynamometry (kg) & $\begin{array}{l}\text { CG } \\
\text { EG }\end{array}$ & $\begin{array}{l}11,66 \pm 0,15 \\
14,04 \pm 0,13\end{array}$ & 11,70 & $\mathrm{p}<0,01$ \\
\hline Romberg test (s) & $\begin{array}{l}\text { CG } \\
\text { EG }\end{array}$ & $\begin{array}{l}5,76 \pm 0,18 \\
11,71 \pm 0,10\end{array}$ & 28,47 & $\mathrm{p}<0,01$ \\
\hline
\end{tabular}


Also the place of application of means of gymnastics in lesson structure has been designated. With that end in view in the beginning of preliminary experiment complexes on development of physical qualities which have been included in all quarters of academic year have been made on the fixed plan for year which provided training and perfection of the basic impellent actions on track and field athletics and outdoor games, and also.

Upon termination of experiment the analysis of dynamics of indicators of physical readiness of pupils of control and experimental groups which has shown has been made, that during experiment physical readiness of experimental group has essentially improved in comparison with control (tab. $3,4)$.

Table 4

\section{Dynamics of indicators of physical readiness of pupils of the first classes of control and experimental groups at the moment of the termination of pedagogical experiment (girl)}

\begin{tabular}{|c|c|c|c|c|}
\hline Control exercises & Group & $\mathrm{X} \pm \sigma$ & tрacч. & $\mathrm{P}$ \\
\hline Run 30m (s) & $\begin{array}{l}\text { CG } \\
\text { EG }\end{array}$ & $\begin{array}{l}7,52 \pm 0,14 \\
6,26 \pm 0,07\end{array}$ & 8,03 & $p<0,01$ \\
\hline Shuttle run $3 \times 10 \mathrm{~m}(\mathrm{~s})$ & $\begin{array}{l}\text { CG } \\
\text { EG }\end{array}$ & $\begin{array}{l}10,95 \pm 0,13 \\
10,44 \pm 0,11\end{array}$ & 2,97 & $p<0,01$ \\
\hline Broad jump about places (sm) & $\begin{array}{l}\text { CG } \\
\text { EG }\end{array}$ & \begin{tabular}{|l}
$109,91 \pm 0,72$ \\
$119,64 \pm 0,64$
\end{tabular} & 10,13 & $p<0,01$ \\
\hline $\begin{array}{l}\text { Flexion and extension of the arms in the } \\
\text { lying position (times) }\end{array}$ & $\begin{array}{l}\text { CG } \\
\text { EG }\end{array}$ & $\begin{array}{l}4,54 \pm 0,37 \\
6,80 \pm 0,55\end{array}$ & 3,43 & $p<0,01$ \\
\hline $\begin{array}{l}\text { Raising straight legs on the gymnastic wall } \\
\text { (times) }\end{array}$ & $\begin{array}{l}\text { CG } \\
\text { EG }\end{array}$ & $\begin{array}{l}5,18 \pm 0,35 \\
7,00 \pm 0,49\end{array}$ & 3,03 & $p<0,01$ \\
\hline High bar pull-up (times) & $\begin{array}{l}\text { CG } \\
\text { EG }\end{array}$ & $\begin{array}{l}4,64 \pm 0,41 \\
8,64 \pm 0,58 \\
\end{array}$ & 5,65 & $p<0,01$ \\
\hline $\begin{array}{l}\text { Raising the torso from a prone position, } \\
\text { hands behind the head in } 30 \text { seconds (times) }\end{array}$ & $\begin{array}{l}\text { CG } \\
\text { EG }\end{array}$ & $\begin{array}{l}10,73 \pm 0,47 \\
13,09 \pm 0,67\end{array}$ & 2,90 & $p<0,01$ \\
\hline Sitting forward bend $(\mathrm{sm})$ & $\begin{array}{l}\text { CG } \\
\text { EG }\end{array}$ & $\begin{array}{l}3,00 \pm 0,33 \\
5.18 \pm 0.48\end{array}$ & 3,73 & $\mathrm{p}<0,01$ \\
\hline "Bridge" from the supine position (sm) & $\begin{array}{l}\text { CG } \\
\text { EG }\end{array}$ & $\begin{array}{l}52,52 \pm 0,37 \\
46,95 \pm 0,21 \\
\end{array}$ & 12,99 & $p<0,01$ \\
\hline Dynamometry $(\mathrm{kg})$ & $\begin{array}{l}\text { CG } \\
\text { EG }\end{array}$ & $\begin{array}{l}10,94 \pm 0,19 \\
12,99 \pm 0,17 \\
\end{array}$ & 8,12 & $p<0,01$ \\
\hline Romberg test (s) & $\begin{array}{l}\text { CG } \\
\text { EG }\end{array}$ & $\begin{array}{l}5,89 \pm 0,18 \\
12,04 \pm 0,15\end{array}$ & 26,58 & $\mathrm{p}<0,01$ \\
\hline
\end{tabular}

Efficiency of the developed technique has proved to be true authentic improvement of indicators of results of testing of boys and girls of experimental group over similar indicators of boys and girls of control group in the end of experiment.
Results of the spent experiment show, that the offered training influences directed on development of speed-power qualities, on development of coordination and flexibility in pupils of the first classes, provide training effect within the limits of an offered technique. 
The best results received for experimental group, in comparison with control, speak that employment under the traditional complex program on physical training for schoolboys of elementary grades on which the control group was engaged, are directed mainly, on development of volume of impellent skills and promote education of physical qualities insufficiently.

The received results have allowed to come to conclusion, that the estimation of results of testing of the basic physical qualities should be differentiated depending on individual characteristics of the child Absolute values of results of testing can be used as reference points at development of those or other physical qualities, but not as criteria of construction of educational process. To manage the pedagogical process with a greater degree of efficiency, directed on improvement of children of 6-7 summer age, it is expedient to define not only initial level of their readiness, but also rates of its gain.

Efficiency of the offered technique was estimated by means of comparison of indicators of physical readiness, a functional condition of cardiovascular system ( heart rate). In experimental group heart rate reached $170 \mathrm{ud} /$ minutes, but within 3-4 minutes pulse was restored to initial level. The analysis of dynamics of frequency of warm reductions on employment in experimental and control groups has shown, that loading in experimental group renders more expressed training effect on an organism of children, in comparison with loading at lessons in control group (156 ud/mines) with the regenerative period till 5 minutes. Thus, data heart rate monitoring, in a certain measure confirm efficiency of an experimental technique (pic1).

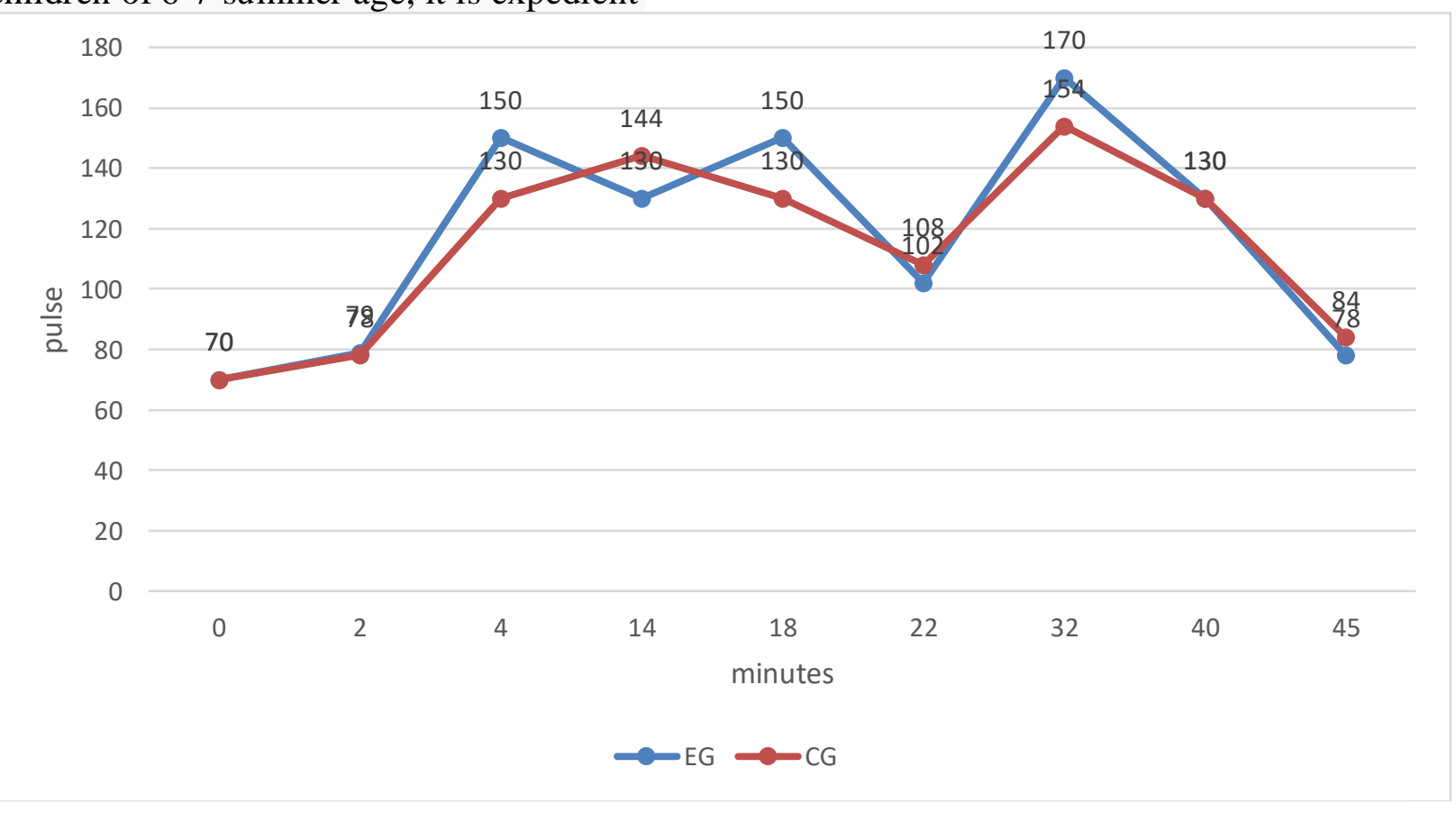

\section{Drawing 1.Dynamics Heart rate during a physical training lesson}

Thus, it is possible to ascertain, that efficiency of the developed technique has proved to be true positive dynamics of results of experimental group in relation to control, and authentic improvement of indicators of results of testing of boys and girls of experimental group. Application of the developed technique in experimental group has essentially increased indicators of development of such impellent abilities, as: coordination of movements (184\% - boys and $168 \%$ of 
the-girls), force of muscles extensors hands (206 \% - boys and $210 \%$ - girls), flexibility (262\% - boys and 96,2 \% girls), force of muscles of an abdominal tension (83\% - boys and $57,3 \%$ of thegirls).

CONCLUSION.Application of offered complexes of exercises for pupils of the first classes at physical training lessons has allowed to expand their impellent outlook at the expense of a considerable quantity various on coordination structure of natural movements and has given the chance to receive necessary physical activity. Use of outdoor games with gymnastics elements does a lesson sated and promotes formation of steady interest of schoolboys to employment by physical training and sports. The experimental technique with the expanded application of means of the gymnastics, proved in pedagogical experiment, considerably raises efficiency of educational process. She allows to develop effectively impellent abilities of children, successfully to form the skills necessary for first-graders and to raise a level of development of physical qualities.

\section{The used literature}

[1] Vavilov E.N. Feature of display of impellent qualities at children of 6-7 years.//a physical training Role in preparation of children for school: Сб. науч. tr./Under the editorship of Y.F.Zmanovsky and N.T.Terehovoy. - M, 2000.

[2] Volkov L.V.A control system of development of physical abilities of children of school age in the course of employment by physical training and sports: dissertation abstract .Dr.sped. Sciences. - M, 2008.

[3] Gaverdovsky Y.K. Technics of gymnastic exercises. The popular manual. - M: a Terra-sports, 2002. 512 with.
[4] LyahV.I. Testy in physical training of schoolboys. - M: Physical culture and sports, 2008

[5] Smolevsky V.M, Gaverdovsky Y.K. Sports gymnastics: Studies. For in phy. a cult. - Kiev: 1999. - 462 with.

[6] Umarov D.X. Technology of development of physical qualities of young gymnasts at the initial stage of preparation // To science-sport. - T., 2007. -№2. - B.10-14

[7] . Umarov M. N, Eshtaev A.K.Planning and distribution of means of training of gymnasts at the preparation initial stage. Studies. The grant. - T: USUPES, 2004.-154 with

[8] Hlebnikova, S.N. Maintenance and a technique of employment by physical training with accentuation on development of physical qualities by gymnastics means//the University bulletin of Smolensk humanitarian university. - 2007. - №1 (13). - P. 87 91

[9] Holodov Z.K., Smiths V.S.Teorija and a physical training and sports technique: Studies. The grant for studen. high. Studies. Institutions. 2. And доп. - M: "Academy", 2002. $480 \mathrm{p}$

[10] Gapparov Z.G.,Ishtaev J.M., Ishtaev D.R., Holmurodov L.Z. Efficiency development explosive abilities at schoolboys of 12-13 years. Solid State technology // Volume: 63 Issue:4. Publication Year:2020. 